\title{
Characterization of terrestrial cyanobacteria to increase process efficiency in low energy consuming production processes
}

\author{
Stephan Kuhne ${ }^{1 *}$, Michael Lakatos ${ }^{2}$, Sarah Foltz ${ }^{2}$, Kai Muffler ${ }^{1}$ and Roland Ulber ${ }^{1^{*}}$
}

\begin{abstract}
Terrestrial cyanobacteria have seldom been used for biotechnological processes, even though they offer great potential for new pharmaceutical products or other value-added substances. Particularly cyanobacteria of xeric habitats are of biotechnological interest, because they tolerate high temperatures, are desiccation-tolerant and feature low water consumption. In addition, the cyanobacteria collected in deserts are able to produce more photoprotective agents than their counterparts from other habitats, because of their genetical preadaptation. In this study, carotenoid and chlorophyll content of two representative terrestrial cyanobacteria strains, i.e. Nostoc muscorum and Leptolyngbya spec. sampled in Columbia (USA) and Soebatsfontein (RSA), were studied after exposure of the strains to different light conditions and cultivation temperatures. A temperature raise from $17^{\circ} \mathrm{C}$ to $30^{\circ} \mathrm{C}$ led to an increase of $46 \%$ in chlorophyll a content as well as an increase of $39 \%$ in carotenoid content of Nostoc muscorum. An irradiation raise from $19 \mu \mathrm{mol} \mathrm{m} \mathrm{s}^{-2}$ to $125 \mu \mathrm{mol} \mathrm{m} \mathrm{s}^{-2}$ resulted in an increase of a 10 to 20 times higher chlorophyll content. Additional results from light-curves support the potential future use of terrestrial cyanobacteria within low energy biotechnological processes using a novel type of photobioreactor to reduce the downstream process costs and nutrients needed during the cultivation. Results indicate that especially light intensity optimization currently holds unused potential.
\end{abstract}

Keywords: Chlorophyll a, Carotenoid, Terrestrial cyanobacteria, Light and temperature variation, Light-curve, Photobioreactor

\section{Background}

The biotechnological utilization of cyanobacteria for the production of valuable compounds has been reported on quite often in the past. However, mainly aquatic cyanobacteria were cultivated until now, because the available fermentation technology is solely submerged [1]. This is due to the fact, that on the one hand the organisms are easy to handle and, on the other hand, mostly marine cyanobacteria were used [2]. Recently, terrestrial cyanobacteria have attracted more attention, because of their important ecological impact in nutrient poor arid and xeric habitats [3]. Terrestrial cyanobacteria adapt well to abiotic environmental conditions, can withstand temperature fluctuations and low water availability [4],

\footnotetext{
* Correspondence: s.kuhne@mv.uni-kl.de; ulber@mv.uni-kl.de

${ }^{1}$ Institute of Bioprocess Engineering, University of Kaiserslautern, D-67663,

Kaiserslautern, Germany

Full list of author information is available at the end of the article
}

and are also capable of producing numerous biologically active- and pharmaceutical important compounds besides extracellular polymeric substances (EPS), such as Cryptophycin, the antiviral Cyanovirin-N \& Scytovirin and Scytonemin [5-7].

Carotenoids are among the pharmaceutically important compounds, which have been revealed to be antioxidants in lipophilic systems to avoid photoinhibition of photosynthesis and photooxidation [8,9]. In this context several studies have shown that the carotenoids can be applied to prevent damages to algal and human tissue caused by solar irradiation [10]. Associated with carotenoids in the photosystem of cyanobacteria is the pigment chlorophyll $a$, which plays a key role in oxygenic photosynthesis. It has been proven that both, the carotenoid and the chlorophyll $a$ content of terrestrial cyanobacteria, are dependent on exposure to solar irradiation [11]. Both pigments are also used as colorants for food 
and textiles. The deserts in Columbia (USA) and Soebatsfontein (RSA) are both considered to be xeric habitats because of the low annual levels of precipitation. Due to their high irradiation and extreme low nutrient availability, these habitats represent one of the harshest environments for photosynthetic organisms. Terrestrial cyanobacteria inhabiting these regions are well adapted to high temperatures and solar irradiation $[11,12]$ and are therefore the ideal subjects for preliminary studies to set up a new bioprocess using a new type of photobioreactor. In order to meet this goal, the optimal setup still has to be discovered and therefore chlorophyll $a$ and carotenoid contents not only serve as possible products but also indicate which conditions might be optimal for cell growth [13,14] Results can be implemented into a process using a new kind of photobioreactor, which optimally meets the special needs of surface associated growing organisms like terrestrial cyanobacteria. Ideally, a photobioreactor would imitate the naturally occurring conditions and offer the possibility to control crucial parameters, which are needed for further optimization. With respect to a subsequent application of terrestrial cyanobacteria in a low energy consuming biotechnological production process of carotenoids, the production of carotenoids and chlorophyll was tested even under high temperatures and low light conditions. A possible emersed photobioreactor design is shown in Figure 1.

\section{Results}

In this study light and temperature dependent differences of chlorophyll $a$ and carotenoid content in terrestrial cyanobacteria were investigated under low light conditions. The mean carotenoid content of $N$. muscorum increased with higher temperatures, from $2,63 \mu \mathrm{g} / \mathrm{g} \mathrm{DW}( \pm 1,3)$ to $3,66 \mu \mathrm{g} / \mathrm{g} \mathrm{DW}( \pm 0,7)$, whereas the mean carotenoid content of Leptolyngbya spec. decreased from $1,31 \mu \mathrm{g} / \mathrm{g} \mathrm{DW}( \pm 0,2)$ to $0,41 \mu \mathrm{g} / \mathrm{g} \mathrm{DW}$ $( \pm 0,03)$ at a temperature shift from $17^{\circ} \mathrm{C}$ to $30^{\circ} \mathrm{C}$ (Figure 2).

The different chlorophyll $a$ contents in relation to temperature and to irradiation are shown in Figure 3. The temperature seems to have a minor effect in comparison to the light, since the chlorophyll $a$ content in $N$. muscorum rose from $2,61 \mu \mathrm{g} / \mathrm{g}$ DW $( \pm 1,2)$ to $3,80 \mu \mathrm{g} /$ g DW $( \pm 0,6)$ at $17^{\circ} \mathrm{C}$ (increase of $46 \%$ from $40 \mu \mathrm{mol} \mathrm{m} \mathrm{m}^{-2}$ $\mathrm{s}^{-1}$ to $125 \mu \mathrm{mol} \mathrm{m} \mathrm{m}^{-2} \mathrm{~s}^{-1}$ ). In Leptolyngbya spec. the chlorophyll $a$ content even decreased, like the carotenoid content, from $1,74 \mu \mathrm{g} / \mathrm{g} \mathrm{DW}( \pm 0,2)$ to $0,23 \mu \mathrm{g} / \mathrm{g} \mathrm{DW}$ $( \pm 0,01)$. The effect of different light intensities has been tested at a fixed temperature of $24^{\circ} \mathrm{C}$ and focused on chlorophyll $a$ production as well. $19 \mu \mathrm{mol} \mathrm{m} \mathrm{m}^{-2} \mathrm{~s}^{-1}$ led to

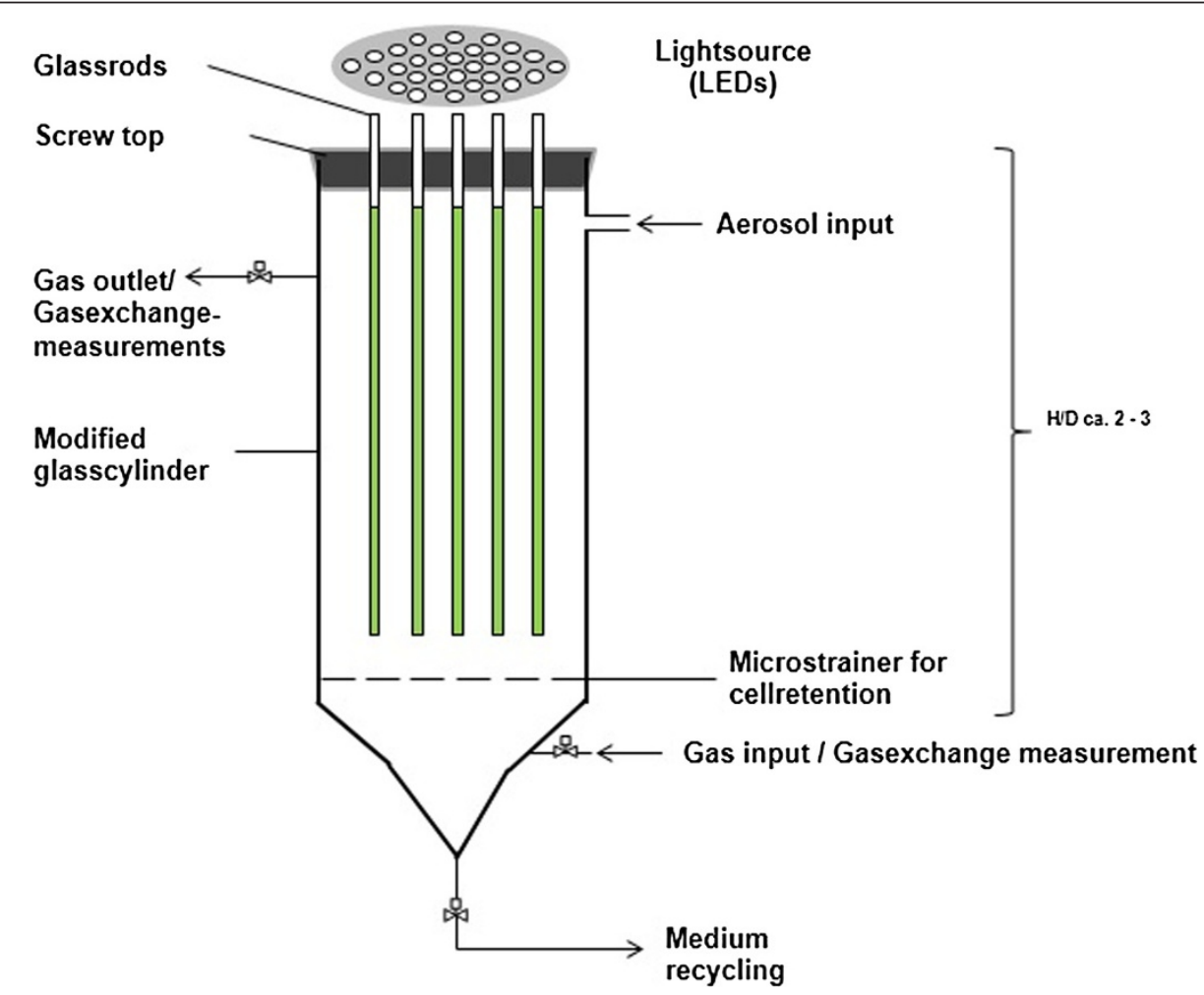

Figure 1 Scheme of emers photobioreactor prototype for potential usage in low energy consuming production processes involving phototrophic organisms like terrestrial cyanobacteria. 

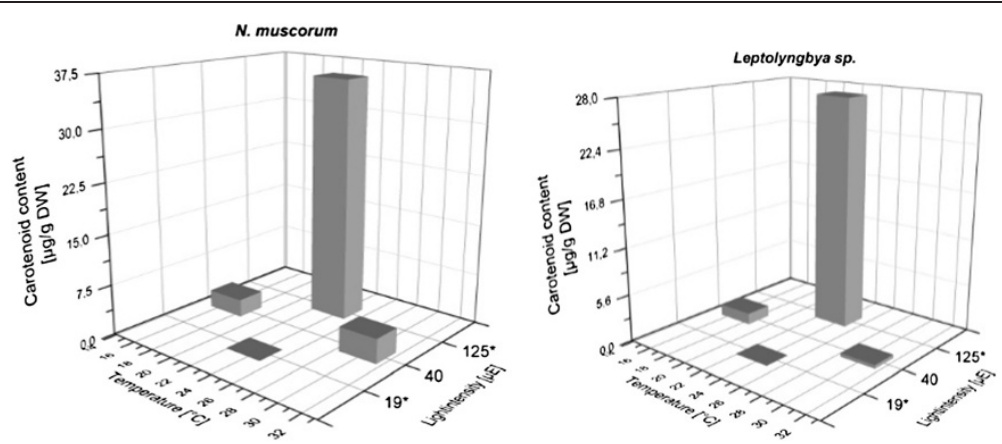

Figure 2 Average carotenoid content of the terrestrial cyanobacteria Nostoc muscorum and Leptolyngbya sp. at $17^{\circ} \mathrm{C}$ and $30^{\circ} \mathrm{C}$ with an irradiation of $40 \mu \mathrm{mol} \mathrm{m} \mathrm{s}^{-1}$ in comparison to $24^{\circ} \mathrm{C}$ and irradiations of $19 \mu \mathrm{mol} \mathrm{m} \mathrm{s}^{-1}$ and $125 \mu \mathrm{mol} \mathrm{m}^{-2} \mathrm{~s}^{-1}$. * values calculated according to the ratio in Table 1.

mortality, as the provided light was apparently not enough for the survival of the cyanobacteria itself. While $125 \mu \mathrm{mol} \mathrm{m} \mathrm{m}^{-2}$ led to a chlorophyll $a$ content of 37,39 $\mu \mathrm{g} / \mathrm{g}$ DW $( \pm 26,1)$ in $N$. muscorum and to $35,39 \mu \mathrm{g} / \mathrm{g}$ DW $( \pm 11,8)$ in Leptolyngbya spec. In comparison to $30^{\circ} \mathrm{C}$ and $40 \mu \mathrm{mol} \mathrm{m} \mathrm{m}^{-2} \mathrm{~s}^{-1}$, the chlorophyll $a$ content of N. muscorum at $24^{\circ} \mathrm{C}$ and $125 \mu \mathrm{mol} \mathrm{m}{ }^{-2} \mathrm{~s}^{-1}$ were ten times higher. Light-response-curve measurements indicate further process efficiency improvement potential regarding the optimal light intensity (Figure 4). T he highest electron transport rates (ETR) for both organisms can be found at light intensities of approximately $550-600 \mu \mathrm{mol} \mathrm{m} \mathrm{m}^{-2} \mathrm{~s}^{-1}$. The ETR $\mathrm{Emax}_{\operatorname{mal}}$ value of Leptolyngbya spec. was $\sim 13 \mu \mathrm{mol} \mathrm{m}{ }^{-2}$ $\mathrm{s}^{-1}$, whereas it was $\sim 33 \mu \mathrm{mol} \mathrm{m} \mathrm{m}^{-2} \mathrm{~s}^{-1}$ regarding Nostoc muscorum.

Due to the association of the chlorophyll $a$ and carotenoid content, the ratio $\frac{\mathrm{Chl}}{\mathrm{Car}}$ has been calculated. In $N$. muscorum the ratio was not altered $(3,41$ to 3,42$)$, but in Leptolyngbya spec. the ratio decreased in favor of the carotenoid content (2,86 to 2,08; Table 1$)$. This implies, that higher temperatures lead to higher relative carotenoid contents. Due to these results and the well-known photoprotective effect of carotenoids, it is assumed that higher light intensities have the same effect concerning the observed organisms. Also the missing values have been calculated.

\section{Discussion}

It has been shown, that the light intensity has an effect not only on the chlorophyll $a$ and carotenoid content, as well as on the composition of the different carotenoids $[11,15]$. In addition, temperature is one of the most important environmental factors and plays a significant role in controlling the organisms' activity [16]. Therefore, the combination of these two aspects is vital in order to achieve high productivity in a potential process using terrestrial cyanobacteria.

The experiments show, that both temperature and light intensity have an effect on chlorophyll $a$ and carotenoid content. Especially in $N$. muscorum a temperature rise of $13^{\circ} \mathrm{C}$ (from $17^{\circ} \mathrm{C}$ to $30^{\circ} \mathrm{C}$ ) led to an increase of $46 \%$ of chlorophyll $a$ and $39 \%$ of carotenoids. Interestingly, Leptolyngbya spec. shows a contrary effect. Chlorophyll $a$ and carotenoids decrease by $86 \%$ and $68 \%$ respectively. This is due to the fact, that both organisms have different growth optima based on temperature. They can tolerate extreme temperatures [16] and have
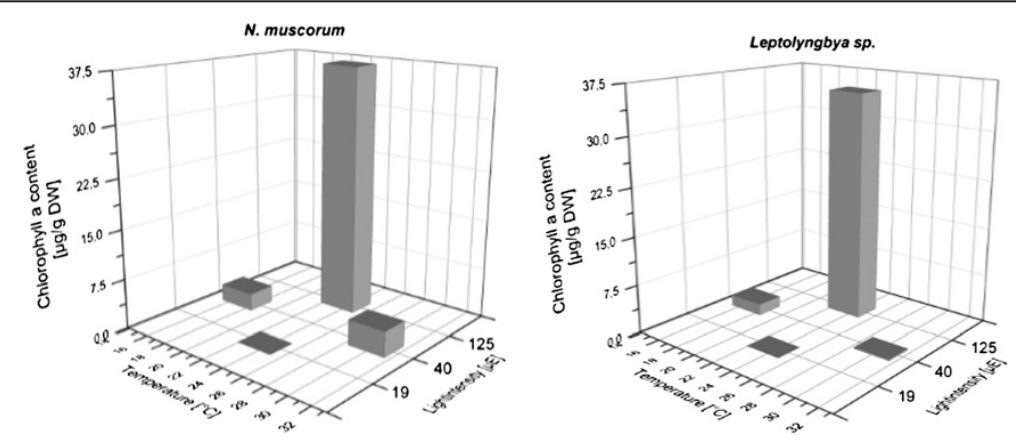

Figure 3 Average chlorophyll a content of the terrestrial cyanobacteria Nostoc muscorum and Leptolyngbya sp. measured at $17^{\circ} \mathrm{C}$ and $30^{\circ} \mathrm{C}$ with an irradiation of $40 \mu \mathrm{mol} \mathrm{m} \mathrm{s}^{-1}$ in comparison to $24^{\circ} \mathrm{C}$ and irradiations of $19 \mu \mathrm{mol} \mathrm{m} \mathrm{s}^{-2}$ and $125 \mu \mathrm{mol} \mathrm{m} \mathrm{s}^{-2}$. 


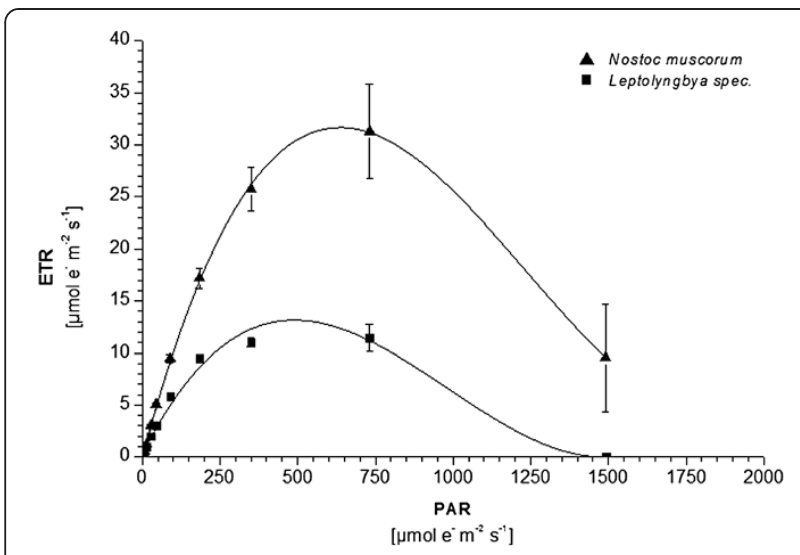

Figure 4 Lightcurves of the terrestrial cyanobacteria Nostoc muscorum and Leptolyngbya spec. at $24^{\circ} \mathrm{C}$ and irradiation varying from $0 \mu \mathrm{mol} \mathrm{e} \mathrm{m}^{-2} \mathrm{~s}^{-1}$ to $1491 \mu \mathrm{mol} \mathrm{e} \mathrm{e}^{-2} \mathrm{~s}^{-1}$, with max. ETR values from $\sim 13 \mu \mathrm{mol} \mathrm{e}^{-1} \mathrm{~m}^{-2} \mathrm{~s}^{-1}$ for Leptolyngbya spec. and $\sim 33 \mu \mathrm{mol} \mathrm{e} \mathrm{e}^{-2} \mathrm{~s}^{-1}$ for Nostoc muscorum.

different mechanisms to control desiccation [17], but in the reported experiments they were cultivated at constant temperatures with sufficient water available to keep their metabolism active. This was done because according to first experiments their growth optima are considered to be between $20^{\circ} \mathrm{C}$ and $35^{\circ} \mathrm{C}$.

The threefold rise in light intensity $\left(40 \mu \mathrm{mol} \mathrm{m} \mathrm{m}^{-2} \mathrm{~s}^{-1}\right.$ to $125 \mu \mathrm{mol} \mathrm{m} \mathrm{m}^{-2} \mathrm{~s}^{-1}$ ) led to an unproportional increase of 10 times more chlorophyll $a$ in N. muscorum (in comparison to $30^{\circ} \mathrm{C}$ ) and 20 times in Leptolyngbya spec. (in comparison to $17^{\circ} \mathrm{C}$ ). The same accounts for carotenoid contents, which increase with rising light intensities, as shown here and in other publications $[11,18,19]$.

In order to calculate the carotenoid content at a light intensity of $125 \mu \mathrm{mol} \mathrm{m} \mathrm{m}^{-2}$ the chlorophyll $a$ to carotenoid ratio (Table 1) was used. The linkage of the two components has been shown through the measured ratio during the experiments (Table 1) and by the ratio [11] reported, which was in the same order of magnitude. Considering this, a carotenoid content level from about $32-40 \mu \mathrm{g} / \mathrm{g} \mathrm{DW}$ in $N$. muscorum and about 25-30 $\mu \mathrm{g} / \mathrm{g} \mathrm{DW}$ in Leptolyngbya spec. is assumed $\left(24^{\circ} \mathrm{C}, 125 \mu \mathrm{mol} \mathrm{m}{ }^{-2} \mathrm{~s}^{-1}\right)$.

In exposed tropical rock habitats of Venezuela terrestrial cyanobacteria produced $553 \mu \mathrm{g} / \mathrm{g}$ DW chlorophyll $a$ and $576 \mu \mathrm{g} / \mathrm{g}$ DW carotenoids under an extreme high natural light regime [11]. These researchers reported

Table 1 Chlorophyll $a$ to carotenoid ratio

\begin{tabular}{lcccc}
\hline Organism & $\mathbf{1 7}^{\circ} \mathbf{C}$ Mean & SD & $\mathbf{3 0}^{\circ} \mathbf{C}$ & SD \\
\hline N.muscorum & 3,41 & 1,08 & 3,42 & 0,24 \\
Leptolyngbya sp. & 2,86 & 0,22 & 2,08 & 0,25 \\
\hline
\end{tabular}

Shown are the mean values $(n=12)$. light intensities of up to $2500 \mu \mathrm{mol} \mathrm{m} \mathrm{m}^{-2} \mathrm{~s}^{-1}$ and peaking surface temperatures of up to $50^{\circ} \mathrm{C}$. The latter study and the measured light curves herein (Figure 4), show the tremendous potential in optimizing the cultivation parameters temperature and especially the light intensity. The temperature optima, though, seem to be below these peaking values. Thus, terrestrial xeric cyanobacteria can be considered interesting production organisms for carotenoid and chlorophyll, especially with regard to a low energy consuming biotechnological production process, using low light conditions.

To meet the scientific findings mentioned above and the special needs of terrestrial cyanobacteria a new photobioreactor design, especially focused on emersed cultivation was developed. A scheme of the reactor prototype is shown in Figure 1. The main parts of the reactor are glass rods, which are positioned in a modified glass-cylinder. A screw top with drillings keeps the rods in position while sealing the cylinder. Light is applied via LEDs positioned above the reactor and nutrients, as well as, water are supplemented as aerosol. Additional installations to the glass-cylinder allow gas control and gas exchange measurements. At the bottom of the reactor the accumulated medium can be recycled. Cells that could be potentially removed by washing are restrained by a micro strainer. Different phototrophic organisms can be cultivated on the surface of the glass rods, where light is applied to them. This special design features various advantages in comparison to classical photobioreactors, such as the possibility of humidity and irradiation regulation, as well as water on hand, for organisms. It is possible to cultivate terrestrial cyanobacteria under controlled and reproducible conditions. Moreover, natural conditions such as circadian rhythms and even humidity or temperature change over day can be imitated. In comparison to outdoor cultivation numbering up and sterility make the photobioreactor ideal for screening desiccation tolerant organisms in general, for example for pharmaceutical processes. Due to medium recycling, the amount of water needed for cultivation and occurring waste can be reduced. Even more importantly, the energy needed for the downstream process can be reduced significantly, because the cells can be dried and retrieved inside the photobioreactor. No further purification, centrifugation and drying is needed. Together with the elimination of energy needed for mixing up to 40 percent of the process costs can potentially be saved $[20,21]$. Kieseler et al. [22] recently pointed out, that about 15 percent resulting algae biomass is needed only to cover the drying costs, which can be avoided using our reactor design ether. With a low required energy-input the reactor also features low energy consuming production and screening demands of nowadays and thus is applicable within further studies 
considering terrestrial cyanobacteria. An additional publication featuring further details of the new photobioreactor is currently in preparation.

\section{Experimental Cultivation}

The terrestrial cyanobacteria Nostoc muscorum (PCC 7906) and Leptolyngbya spec. (BB 2292(5)1) isolated from xeric habitats on soil in Columbia (USA) and Soebatsfontein (RSA) respectively, were cultivated both under the same light conditions $\left(40 \mu \mathrm{mol} \mathrm{m} \mathrm{m}^{-2}\right)$ at different temperatures $\left(17^{\circ} \mathrm{C}\right.$ and $\left.30^{\circ} \mathrm{C}\right)$ and with the same temperature $\left(24^{\circ} \mathrm{C}\right)$ but at different low light conditions $\left(19 \mu \mathrm{mol} \mathrm{m} \mathrm{m}^{-2} \mathrm{~s}^{-1}\right.$ and $\left.125 \mu \mathrm{mol} \mathrm{m} \mathrm{m}^{-2} \mathrm{~s}^{-1}\right)$. The response to light was analyzed with rapid light response curves, determined by chlorophyll $a$ fluorescence. Photosynthetic saturation between photosynthetic flux densities of 600 and $800 \mu \mathrm{mol} \mathrm{m} \mathrm{m}^{-2} \mathrm{~s}^{-1}$ was revealed. This indicates that the strains were investigated while they were still in the linear increase of light limitation at the applied light intensities. The cultivation took place in temperature controlled photo incubators (program-controlled Incubator, Type KBP, Series 2000, Tritec Hannover, D) for 4 weeks and liquid cyanobacteria medium BG11 was used. The temperature and humidity was measured with miniaturized data logger (i-Buttons, Maxim Integrates products, Inc., Sunnywvale, CA, USA). The duration of light exposure was 14/10 hrs. and the light intensities were measured with a quantum sensor (Licor 190A, LicorBiosciences Lincoln, NE, USA).

\section{Culture preparation}

The cultures were homogenized using glass balls $(0,5$ mm diameter) and a swing mill (Retsch MM200; Retsch $\mathrm{GmbH}$, Haan, D) for $90 \mathrm{sec}$ at a frequency of $20 \mathrm{~s}^{-1}$. The dry weight was determined using a volume of $500 \mu \mathrm{L}$ of the homogenized culture for centrifugation at $10,600 \mathrm{~g}$ and drying afterwards at $60^{\circ} \mathrm{C}$. The optical density (OD) was measured at a wavelength of $665 \mathrm{~nm}\left(\mathrm{OD}_{665}\right)$ in 96well micro plates (PS-Micro plate, 96-well, colorless; Greiner Bio-One GmbH, Frickenhausen, D) using a micro plate Spectrophotometer (Epoch micro plate, BioTek Germany, Bad Friedrichshall, D). Both parameters were correlated to pigment contents to calculate the chlorophyll $a$ and carotenoid content on a dry weight basis in $[\mu \mathrm{g} / \mathrm{g} \mathrm{DW}]$.

\section{Pigment analysis}

The chlorophyll $a$ and carotenoid extraction were modified according to Porra and co-workers (1989). For each extraction a culture volume of $300 \mu \mathrm{L}$ was sampled in an $1.5 \mathrm{~mL}$ reaction-vessel and centrifuged for $12 \mathrm{~min}$ at $10,600 \mathrm{~g}$. The supernatant was discarded and $500 \mu \mathrm{L}$ methanol, containing $20 \mathrm{mg}$ of $\mathrm{CaCO}_{3}$, was added. The main extraction took place in a water bath at $65^{\circ} \mathrm{C}$ for $60 \mathrm{~min}$. After extraction the sample was centrifuged for $12 \mathrm{~min}$ at $10,600 \mathrm{~g}$. The supernatant was put into an $1.5 \mathrm{~mL}$ reaction-vessel and stored at $4^{\circ} \mathrm{C}$. The pellet was used for a second extraction with the same conditions and afterwards the supernatants were pooled. In order to determine the chlorophyll and carotenoid content 300 $\mu \mathrm{L}$ of the supernatant was put into a 96-well micro plate. The absorption was measured at wavelengths of $461 \mathrm{~nm}$, $665 \mathrm{~nm}$ and $652 \mathrm{~nm}$. The carotenoid content was calculated according to the modified formula from Chamovitz and co-workers (1993):

$$
\begin{aligned}
& \text { Carotenoid content }[\mu \mathrm{g} / \mathrm{mL}] \\
& \quad=\left[\mathrm{OD}_{461}-\left(0,046 \times \mathrm{OD}_{665}\right)\right] \times 4
\end{aligned}
$$

and respectively the chlorophyll $a$ content was calculated according to Porra and co-workers (1989):

$$
\text { Chlorophyll a }[\mu \mathrm{g} / \mathrm{mL}]=16,29 \times \mathrm{OD}_{665}-8,52 \times \mathrm{OD}_{652} \text {. }
$$

\section{Light-response-curve measurement}

Light-response-curve measurements were carried out with an imaging fluorometer (Imaging-PAM, Heinz Walz GmbH, Effeltrich, D). During light exposure the instantaneous fluorescence (Ft), and after the application of a light saturation pulse, the maximal fluorescence of photosystem II after light adaption $\left(\mathrm{F}_{\mathrm{M}}\right.$ ') were measured. Both of them are needed for calculation of the effective quantum yield ([23,24]; equation 3 ) and a further calculation of the apparent electron transport rate (ETR; equation 4).

$$
\begin{aligned}
& \text { Yield }=\left(\mathrm{F}_{\mathrm{M}}{ }^{\prime}-\mathrm{F}_{\mathrm{t}}\right) / \mathrm{F}_{\mathrm{M}}{ }^{\prime} \\
& \mathrm{ETR}=0,5 \times \text { Yield } \times \text { PAR }
\end{aligned}
$$

\section{Conclusions}

It has been shown, that terrestrial cyanobacteria feature interesting properties regarding biotechnological production processes. Due to their genetical preadaptation to light, temperature and desiccation stress cyanobacteria are less sensitive to fluctuations regarding these parameters during production processes. Because of their adaption to high irradiation, a photoinhibition which is often considered a problem during the cultivation of phototrophic organisms, is far less likely and their desiccation tolerance makes them ideal for low energy consuming processes. This is due to the fact, that less water and medium itself is needed during the cultivation process and direct lighting via sunlight (after a possible upscale) can be used more easily. Our data shows the 
tremendous influence of light and irradiance on the formation of this exemplary products, whereas the temperature plays a minor role. As shown in this paper, a special photobioreactor design for emersed cultivation of phototrophic organisms, can contribute further to the optimization of a biotechnological process using terrestrial cyanobacteria. To make a future industrial application more likely the costs related to the downstream process can be reduced significantly because no energy is needed for mixing, centrifugation, purification or drying and less waste is created. That leads to a process, which is much more sustainable than already existing bioprocesses and especially than comparable chemical ones.

This preliminary study draws attention to a currently underexploited group of microorganisms and shows first data regarding possible cultivation parameters. By applying this novel type of photobioreactor this resource can efficiently be tapped for several biotechnological production processes.

\section{Competing interests}

The authors declare that they have no competing interests.

\section{Authors' contributions \\ SK: assistance to experiments, realization of photobioreactor-concept, prepared manuscript. ML: cyanobacteria selection, light response curve measurement, initial photobioreactor idea. SF: experimental work regarding chlorophyll a and carotenoid measurement. KM: optimization of photobioreactor concept, prepared manuscript. RU: elaboration of main photobioreactor concept, technical expertise, prepared manuscript. All authors read and approved the final manuscript.}

\section{Acknowledgements}

This research was supported by the Deutsche Forschungsgemeinschaft (UL 170/7-1, LA 1026/9-1). The research team would like to thank Sandra Meck and Christian Seebach for their assistance during the experiments.

\section{Author details}

${ }^{1}$ Institute of Bioprocess Engineering, University of Kaiserslautern, D-67663, Kaiserslautern, Germany. ${ }^{2}$ Experimental Ecology, University of Kaiserslautern, D-67663 Kaiserslautern, Germany.

Received: 22 February 2013 Accepted: 28 May 2013

Published: 12 June 2013
6. Bewley CA, Gustafson KR, Boyd MR, Covell DG, Bax A, Clore GM, Gronenborn AM: Solution structure of cyanovirin-N, a potent HIV-inactivating protein. Nat Struct Biol 1998, 5:571-578.

7. Muller-Feuga A, Moal J, Kaas R: The microalgae for aquaculture. In Life feeds in marine aquaculture. Edited by Stottrup JG, McEvoy LA. Oxford: Blackwell; 2003.

8. Krinsky NI: Carotenoid protection against oxidation. Pure App/ Chem 1979, 51:649-660.

9. Palozza P, Krinsky NI: Antioxidant effects of carotenoids in vivo and in vitro: an overview. Methods Enzymol 1992, 213:403-419.

10. Heinrich U, Tronnier H: Systemische Fotoprotektion durch Carotinoide. Zeitschrift für Phytotherapie 2010, 31:185-187.

11. Lakatos M, Bilger W, Büdel B: Carotenoid composition of terrestrial cyanobacteria: response to natural light conditions in habitats in Venezuela. Eur J Phycol 2001, 36:367-375.

12. Lüttge U, Kluge M, Bauer G: Botanik. Darmstadt: Wiley-VCH; 2005.

13. Brougham RW: The Relationship between the Critical Leaf Area, Total Chlorophyll Content, and Maximum Growth-rate of some Pasture and Crop Plants. Ann Bot 1960, 96:463-474.

14. Eppley RW, Sloan PR: Growth Rates of Marine Phytoplankton - Correlation with Light Absorption by Cell Chlorophyll Alpha. Physiol Plant 1966, 19(1):47

15. Bilger W, Bohuschke M, Ehling-Schulz M: Annual time courses of the contents of carotenoids and uv-protective pigments in the cyanobacterium nostoc commune. In J. Cramer in Der Gebrueder Borntraeger Verlagsbuchhandlung. Berlin, Germany: E. Schweizerbart'sche Verlagsbuchhandlung: Stuttgart, Germany; 1997.

16. Brock TD: Life at high temperatures. Science 1967, 158:1012-1018.

17. Potts M: Desiccation Tolerance of Prokaryotes. Microbiol Rev 1994, 58:755-805.

18. Vincent WF, Downes MT, Castenholz RW, Howard-Williams C: Community structure and pigment organisation of cyanobacteria dominated microbial mats in Antarctica. Eur J Phycol 1993, 28:213-221.

19. Leisner JMR, Bilger W, Czygan FC, Lange OL: Lipophilous carotenoids of cyanobacterial lichens from different habitats, including an extreme desert site. Cryptogamic Botany 1993, 4:74-82

20. Davis R, Aden A, Pienkos PT: Techno-economic analysis of autotrophic microalgae for fuel production. Appl Energ 2011, 88(10):3524-3531.

21. Norsker NH, Barbosa MJ, Vermuë MH, Wijffels RH: Microalgal production A close look at the economics. Biotechnol Adv 2011, 29(1):24-27.

22. Kieseler S, Neubauer $Y$, Zobel N: Ultimate and Proximate Correlations for Estimating the Higher Heating Value of Hydrothermal Solids. Energy Fuel 2013, 27(2):908-918.

23. Krause $\mathrm{GH}$, Weis E: Chlorophyll fluorescence and photosynthesis: The basis. Ann Rev Plant Physiol Plant Mol Biol 1991, 42:313-349.

24. Bilger W, Schreiber U, Bock M: Determination of the quantum efficiency of photosystem II and of non-photochemical quenching of chlorophyll a fluorescence in the field. Oecologia 1995, 102:425-432.

doi:10.1186/2043-7129-1-6

Cite this article as: Kuhne et al:: Characterization of terrestrial cyanobacteria to increase process efficiency in low energy consuming

production processes. Sustainable Chemical Processes 2013 1:6.

\section{References}

1. Pulz O: Photobioreactors: production systems for phototrophic microorganisms. Appl Microbiol Biotechnol 2001, 57:287-293.

2. Putz O, Gross W: Valuable products from biotechnology of microalgae. Appl Microbiol Biotechnol 2004, 65:635-648.

3. Belnap J, Lange OL: Biological Soil Crusts: Structure, Function and Management. Berlin Heidelberg: Springer; 2001

4. Rascher U, Lakatos M, Büdel B, Lüttge U: Photosynthetic field capacity of cyanobacteria of a tropical inselberg of the guiana highlands. Eur $J$ Phycol 2003, 38:247-256.

5. Boyd MR, Gustafson KR, McMahon JB, Shoemaker RH, O’Keefe BR, Mori T, Gulakowski RJ, Wu L, Rivera MI, Laurencot CM, Currens MJ, Cardellina JH, Buckheit RW, Nara PL, Pannel LK, Sowder RC, Hender LE: Discovery of cyanovirin- $\mathrm{N}$, a novel human immunodeficiency virus-inactivating protein that binds viral surface envelope glycoprotein gp120: potential applications to microbicide development. Antimicrob Agents Chemother 1997, 41:1521-1530. 